\title{
RESENHAS
}

\section{GOMES, P.C.C. QUADROS GEOGRÁFICOS: UMA FORMA DE VER, UMA FORMA DE PENSAR $1^{\mathrm{a}}$ ed. Rio de Janeiro: Bertrand Brasil, 2017}

\section{Ana Betânia de Sousa Pimentel Martins*}

Universidade Federal de Pernambuco

"Quadros geográficos" (2017) é o mais recente livro lançado pelo geógrafo Paulo César da Costa Gomes, autor de outros títulos bastante conhecidos por profissionais da Geografia e áreas afins, como "Geografia e Modernidade" (1996), "Condição urbana" (2003) e "O lugar do olhar" (2013). É resultado de uma longa reflexão, como atestam seus escritos anteriores (Gomes e Ribeiro, 2013, Gomes, 2007; 2002;) que indicam que há pelo menos duas décadas Gomes tem se debruçado sobre o estudo das relações entre imagem e Geografia, bem como sobre as particularidades de seu uso na pesquisa geográfica. Logo, conforme sua nota introdutória, o livro não está diretamente associado a nenhum campo empírico específico, apesar de se apoiar na prática do autor com a pesquisa, o exercício da docência e a orientação de alunos no ensino superior na UFRJ, onde é professor do departamento de Geografia desde 1995'. É, portanto, como aponta Vicent Berdoulay no prefácio do livro (GOMES, 2017, p. 9) - uma obra da "plena maturidade" de Gomes.

O objetivo do livro pode ser sucintamente definido nesta resenha ${ }^{2}$ como defender a tese de que "a Geografia

1 Informações coletadas a partir do currículo Lattes do autor. Disponível em: <http://buscatextual.cnpq.br/buscatextual/visualizacv. do?id=K4781463E1\#ArtigosCompletos>

2 Esta resenha foi escrita inicialmente para atender a avaliação da disciplina Abordagens contemporâneas em Geografia Cultural ofertada pelo PPGEO UFPE ministrada pelo prof. Dr. Caio A.A. Maciel à quem agradecemos o incentivo e a orientação. é uma forma de pensar", afirmação reiterada diversas vezes durante a obra (GOMES, 2017, p. 8; 13; 21). Uma forma de pensar "original", que parte necessariamente do conhecimento "físico3", dado pela consideração das relações espaciais entre objetos e fenômenos.

Esse raciocínio enfoca duas características principais de uma composição de elementos observáveis: "localização e situação" desses elementos, coisas, ações, objetos, processos, etc. Tal enfoque, ou melhor, enquadramento, distingue-se justamente por priorizar o saber construído a partir do delineamento das "conexões" ou relações físico-espaciais. Nessa construção do conhecimento, constituem-se, por sua vez, os "quadros geográficos", conceito central da argumentação e o que dá nome ao livro (p. 56).

Desse modo, os "quadros geográficos" seriam interpretações e formas de análise criadas a partir de uma visão sobre o arranjo espacial dos elementos ( $p$. 43). Para Gomes (2017), os quadros emergem por meio da realização de um procedimento que é parte crucial da elaboração do pensamento humano e, por conseguinte, também da elaboração da pesquisa científica em Geografia: a descrição, que ganha merecido destaque durante todo o livro.

Já no início do livro, o autor coloca que a Geografia

30 termo físico, utilizado por Gomes, é extraído dos fundamentos epistemológicos de Kant sobre a existência de dois procedimentos básicos pelos quais o ser humano conhece a realidade: a descrição lógica e a física. (pgs. 23-27)" 
apresentaria "o mundo" com base nessas relações espaciais e o faria essencialmente por meio de descrições (GOMES, 2017, p. 25). Estas não se assemelhariam a listas ou inventários exaustivos (GOMES, 2017, p. 25) da realidade. Ao contrário, por não se pretender totalizante, no sentido de funcionar como uma "varredura", a descrição deve partir de critérios previamente definidos, tendo como guia uma "ordem espacial" (GOMES, 2017, p. 121). A descrição em Geografia deve evidenciar as conexões possíveis entre os objetos e fenômenos a partir da compreensão de sua localização e situação.

No tópico específico sobre esse assunto - "Modos e instrumentos da descrição" - Gomes alerta para a distinção entre declaração e descrição, colocandose claramente avesso à primeira forma de apresentar a realidade. Isso porque, para o autor, declarar não seria uma maneira de estimular nem o debate, nem a imaginação geográfica. No caso em que um pesquisador faz uma declaração de seu pensamento, os recursos utilizados para isso, e aqui parece estar se referindo eminentemente ao uso das imagens, serviriam apenas para comprovar o pensamento de quem descreve, ou como "peças de convicção" (GOMES, 2017, p. 125).

A esta altura do livro, pode-se sentir certa tensão momentânea, pois paira a dúvida sobre como separar a descrição da declaração? Não se reconhece, desde a crítica ao Positivismo que nossas convicções, em certa medida, também tocam nossas descrições sobre os objetos de estudo científicos, no caso em Geografia? Sim, certamente e o autor não questiona este entremeio. No entanto, uma releitura mais atenta do próprio livro nos leva a perceber que, ao propor essa distinção, o autor nos chama a atenção para o cuidado necessário envolvido no exercício descritivo na pesquisa geográfica. Deve se evitar lançar conclusões apriorísticas sobre seus próprios quadros geográficos, apegando-se por demais a eles como "peças de conviç̧ão". Pelo contrário, antes, devemos tratá-los como uma plataforma de trabalho da qual possam emergir também novas ideias.

(...) 0 que queremos chamar a atenção é para a distinção de procedimentos descritivos. (...). Descrições que são ilustrações de um raciocínio são declarações, descrições que são sistemáticas, não anedóticas, que têm compromisso com a observação rigorosa, podem ser usadas para nos fazer pensar a partir de novas conectividades. E nesse último caso estamos nos referindo aos quadros geográficos. (GOMES, 2017, p. 127)

No decorrer dos capítulos, Gomes (2017) recupera diferentes exemplos de descrições que criam imagens dentro e fora da Geografia. Fora da Geografia, e demonstrando conhecimento erudito sobre diferentes manifestações culturais - como já havia feito também em "o Lugar do olhar" -, o autor recorre diversas vezes às imagens criadas no campo das artes ${ }^{4}$ visuais, com especial referência a pinturas europeias, como a pintura holandesa na Europa (GOMES, 2017, p. 29-31) e a pintura de paisagem renascentista francesa (GOMES, 2017, p.107-108).

Mas é na demonstração das maneiras de descrever desenvolvidas por grandes nomes da Ciência Geográfica que a ideia dos "quadros geográficos" ganha contornos mais claros para o leitor. Dentre os exemplos de descrição trabalhados no livro, destacam-se os excertos das descrições dos aspectos morfológicos e culturais das regiões da França realizadas pelo próprio Vidal de La Blache (GOMES, 2017, p. 110-115), grande ícone da geografia descritiva ${ }^{5}$ francesa; Outro exemplo esclarecedor seria o que se refere à contribuição dos desenhos no trabalho do geógrafo Pierre Deffontaines ao tratar da sociedade canadense (GOMES, 2017, p. 127129).

Desse modo, ao fazer esse esforço bem sucedido de colocar em diálogo formas de descrever graficamente o pensamento geográfico, é que Gomes chega à descrição da natureza por Humboldt, figura fundamental da Geografia moderna e que assume enorme centralidade no livro aqui resenhado.

Neste capítulo, o autor se dedica a pormenorizar os detalhes da figura "Naturgemälde" que, cabe dizer, foi escolhida como imagem da capa de "Quadros geográficos". Talvez, por ser uma imagem muito emblemática tanto do conceito de "quadro geográfico", quanto da maneira de se fazer uma descrição "viva" (GOMES, 2017, p. 27) - no caso da geografia das plantas naquele ambiente investigado pelo naturalista (GOMES, 2017, p. 37-43).

Nesta exposição de "Naturgemälde", o autor faz um mergulho no contexto histórico de produção dessa imagem por Humboldt, procurando demonstrar que os procedimentos de descrição e representação gráfica tomados por aquele renomado naturalista e grande precursor da geografia Moderna se constitui na criação de um quadro geográfico. E é importante destacar que, além de uma descrição exemplar, para Gomes, aquela imagem da distribuição geográfica das plantas por altitude pode ser considerada também um pioneiro

4 Também é digna de nota a distinção entre a descrição visual operada pela pintura e a àquela feita pela poesia que Gomes pinça a partir da retomada da descrição feita por Nobert Elias do quadro francês do século XVII a peregrinação para a Citera (107-108)

5 É importante pontuar que Gomes faz ressalvas sobre o rótulo de "descritivo" aposto à La Blache, discordando dessa visão restrita sobre a obra do geógrafo francês. 
Sistema de Informações Geográficas (GOMES, 2017, p. 41-42).

Ressalta, desse modo que, aquela pintura da paisagem por conter as informações geográficas de localização e situação dos elementos observáveis teria sido catalisadora do desenvolvimento da teoria de Humboldt. A partir daí, o livro encontra força para seu principal argumento: a geografia é uma forma de pensar, pois parte da necessidade de descrever as conexões espaciais e esse tipo de raciocínio exige a criação de um arcabouço imagético, que por sua vez ajuda a pensar a realidade delimitada por esses "quadros".

Além dessa figura produzida pelo naturalista Alemão, Gomes também recorre a outros exemplos como mapas temáticos diversos e às isolinhas como imagens resultantes da construção de quadros geográficos:

Podemos, por isso, afirmar sem medo que construímos 'quadros' para que eles nos deixem ver - não aquilo que já sabemos, mas aquilo justamente que nos é revelado pela análise das formas e das composições que se delineiam pelas infinitas escolhas que podemos proceder. (GOMES, 2017, p. 57)

Assim, Paulo César da Costa Gomes retoma uma afirmação posta em trabalho anterior de que há na pesquisa em Geografia um "imperativo gráfico", pois é imprescindível pensar com as imagens, já que elas não são meras ilustrações. Pelo contrário, são ferramentas de trabalho do pensamento geográfico para construção de teorias eminente explicativas com base numa visão espacial (GOMES, 2013, p. 60).

Neste novo livro, Gomes não somente retoma seus escritos, mas expande a reflexão sobre o papel da imagem na pesquisa geográfica para pensá-las como uma condição epistemológica do próprio raciocínio da disciplina, tomando como base para isso a leitura e apresentação de obras de referência de pensadores renomados na Geografia.

A grande força deste argumento é que as imagens criadas com os quadros nos fazem ver conexões e aspectos destas que ainda não enxergamos pela visão comum. Os quadros resultantes da observação acurada são terreno fértil para aquilo que o autor chama de imaginação geográfica, isto é, "instrumentos da descoberta" (GOMES, 2017, p. 132).

Assim, ainda que rápido e incompleto, o percurso realizado aqui nos permite afirmar que a imaginação geográfica parece ser provocada pelo uso inteligente das imagens, aquilo que chamamos de 'quadro geográfico'. Esses quadros são sistemas de informações geográficas que se apresentam sob variadas formas gráficas, e no limite até sob a forma de texto. A partir de uma base locacional dos dados, são criadas condições de 'visualização' da posição, da forma e do tamanho dos fenômenos estudados. A possível conectividade entre eles é dada pela localização. Essas lógicas locacionais estão também relacionadas com a capacidade de imaginação, ou seja, embora de forma diferente, há um forte potencial para imagens textuais ou visuais produzirem novas imagens. (GOMES, 2017, p. 140)

Essa afirmação de Gomes é, de fato, muito útil para pensar as diferentes representações gráficas e, ainda mais, para pensar o desdobramento de sua utilização em contextos de decisão sobre intervenções concretas em espaços físicos e públicos da cidade, por exemplo.

Uma necessária observação sobre a afirmação do mapa ser um quadro

$\mathrm{Na}$ terceira seção da obra em tela o autor afırma: "O mapa tem sido frequentemente apontado como um instrumento de base da ação de pensar geograficamente. Por esse motivo, é concebido como imagem padrão para exprimir as características geográficas dos fenômenos." E acrescenta ainda que, com base nessas semelhanças gerais entre pinturas, desenhos e outras formas de representação gráficas que servem para a descrição e o pensamento geográfico, ele inclui o mapa nessa lista "tal qual a composição de um quadro em que figura uma paisagem", afirmando que o mapa seria um quadro assim como os demais.

Nesse ponto, concordamos que o mapa pode ser pensado como um quadro que representa um recorte da realidade e que apresenta uma composição de elementos que estão ali relacionados segundo sua posição, extensão e de acordo com suas próprias morfologias e a do substrato físico (FARINELLI, apud GOMES, 2017, p. 36).

No entanto, se nos for permitido acrescentar algo, gostaríamos de dizer que o mapa não é qualquer quadro, como pode parecer. Sua distinção em relação as demais formas de representação pictórica é dada em função do mapa ser, sim, de fato, um quadro geográfico por princípio, pois seu formato foi originalmente concebido para localizar, situar e orientar a ação no espaço, seja de permanência, de deslocamento, de busca ou de desvio. 0 mesmo não se pode dizer genericamente de uma fotografia ou de uma pintura de paisagem, por exemplo, cuja função estética se destaca às demais.

Ao examinarmos atentamente as características específicas do mapa, percebemos ainda diferenças quanto a sua linguagem gráfica; esta assume feição 
de código, pois não se dá puramente por analogia morfológica a realidade, mas pode ser abstrata e, por vezes, de difícil interpretação. É uma linguagem própria, envolve o uso de símbolos, escalas e legendas as quais estão articuladas na construção do produto cartográfico a fim de garantir o que se chama de "comunicação cartográfica" (BERTIN, 1978). Nem todo quadro utiliza essa linguagem. Desenhos livres e pinturas podem ser polissêmicas. Já as representações cartográficas precisam repassar informação de forma monossêmica, pois no mapa cada informação carrega um sentido que precisa corresponder a um lugar específico de ocorrência.

Quanto à perspectiva proporcionada pelo mapa, em geral, é a ortogonal, ofertando uma visão "de cima" do espaço. Assim o mapa é um quadro específico determinado também pela visão azimutal e pela construção de simbologias as quais querem representar relações de ordem ou proporcionalidade, diversidade conforme preconizou Bertin (1978), um dos principais pensadores da semiologia gráfica ${ }^{6}$.

É notório que o avanço e a popularização das tecnologias tenham aproximado muito os mapas do cotidiano de nossas vidas. Assim, é preciso ajustar o foco para perceber os diferenciais de pensar com os mapas, reconhecendo a complexidade das funções cognitivas mobilizadas sua leitura que envolve não só um olhar interpretativo, mas o domínio da conversibilidade de operações matemáticas para compreensão das escalas e tamanho dos objetos, a coordenação de perspectivas ortogonal, voo de pássaro e a partir do olhar terrestre, entendimento das projeções que distorcem sobremaneira representação do globo terrestre, entre outros etapas ligadas à confecção e leitura de mapas.

0 mapa de fato é um quadro geográfico como coloca Gomes. Emblemático quanto o "Naturgemälde", pois também traz de forma explícita a intenção de direcionar o olhar do leitor para as conexões entre os elementos do espaço delimitado por um recorte, cujos critérios básicos, entre outros possíveis, passam pela escolha da escala e do tema do mapa.

Essa reflexão sobre a especificidade do quadro geográfico do tipo mapa nos leva a sugerir uma abertura necessária para a consideração atenta das diferenças entre os diversos formatos de quadros que são amiúde mobilizados no raciocínio geográfico (fotografias, filmes, croquis, pinturas de paisagem, etc.), de modo a tornar

6 Segundo Bertin (1978), a comunicação da informação cartográfica baseiase na relação entre o Cartógrafo, o mapa e o leitor. 0 cartógrafo deve produzir um mapa em que a classificação dos dados seja representada por símbolos que expressem visualmente as relações de diferença, ordem e proporção de tal modo que o leitor possa distingui-los, sem ambiguidades. claras suas potencialidades, limitações e correlações para os diferentes estudos em suas especificidades. 


\section{Referências}

GOMES, P. C. C. O Lugar do olhar: elementos para uma geografia da visibilidade. Rio de Janeiro: Bertrand Brasil, 2013. Cenários para a Geografia: Sobre a espacialidade das imagens e suas significações. In: ROSENDAHL, Z.; CORRÊA, R. (Org.). Espaço e Cultura: pluralidade temática. Rio de Janeiro: EDUERJ, 2007, p. 187-210. A condição urbana: ensaios de geopolítica. Rio de Janeiro: Bertrand, 2003.

A cultura pública e o espaço: desafios metodológicos. In: CORRÊA, R. L. \& ROSENDAHL, Z. Religião, identidade e território. Rio de Janeiro: EDUERJ, 2001.

GOMES, P.C.C.; RIBEIRO, L. P (2013). A produção de imagens para a pesquisa em Geografia. Espaço e Cultura, Rio de janeiro, n. 33, p. 27-42.

BERTIN, J. Teoria da Comunicação e Teoria da Representação Gráfica. 1978. In: Geocartografia: textos Selecionados de Cartografia Teórica pelo Grupo de estudos em Cartografia Temática da Universidade de São Paulo- GECART. Marcello Martinelli (Trad.). São Paulo, n.13. 1996. 